\title{
25 Research Suare \\ Food-Based Dietary Patterns among Low-Income Single Mothers in Terengganu, Malaysia
}

suriyani muhamad ( $\square$ suriyani_md@umt.edu.my )

Universiti Malaysia Terengganu https://orcid.org/0000-0002-9928-8993

Yulita Yulita

Universiti Malaysia Terengganu

Nor Ermawati Hussain

Universiti Malaysia Terengganu

Noor Haslina Mohamad Akhir

Universiti Malaysia Terengganu

Noorhaslinda Kulub Abdul Rashid

Universiti Malaysia Terengganu

Nizam Ahmat

Universiti Malaysia Terengganu

Research article

Keywords: Single mothers, Lower Socioeconomic status (SES), Body Mass Index (BMI), Food Pyramid

Posted Date: September 4th, 2020

DOl: https://doi.org/10.21203/rs.3.rs-66902/v1

License: (c) (i) This work is licensed under a Creative Commons Attribution 4.0 International License.

Read Full License 


\section{Abstract}

Background: The study is to explore food consumption based on the Malaysian Food Pyramid guideline and dietary related issues among low-income single mothers classified by their Body Mass Index (BMI).

Methods: Data were obtained from 519 low-income, single mothers who resided in Kuala Nerus, a district in the state of Terengganu in Malaysia. This study employed the Chi-square test to identify the differences in the tested parameters between the lean/normal and overweight/obese subjects.

Results: The current study presented the information of single mothers with low-income, and their food consumption and preference based on the Malaysian Food Pyramid. The subjects were categorised into lean/normal BMI of $<25$ and an overweight/obese BMI of $>25$. There were significant differences ( $\mathrm{p}$ value $<0.05$ ) in the food consumption for the food categories of rice, noodles, bread and cereals and vegetables and fruits between the lean/normal and overweight/obese subjects. Nevertheless, there were insignificant differences ( $p$-value $>0.05$ ) in the food consumption for the food categories of dairy, fish, chicken, meat, legumes and fat, oil, sugar and salt between lean/normal and overweight/obese subjects. There were also mixed results on the dietary related issue between the lean/normal and overweight/obese subjects.

Conclusion: Even though there were differences in food consumption of two food categories between both BMI groups, the food consumption was closely consistent with the Malaysian Food Pyramid guideline. The findings had provided relevant evidence and also call for a necessary action from stakeholders to support a healthy diet and nutrition intake, not limited to low-income single mothers', but also other lower socioeconomic status (SES) groups.

\section{Background}

Studies had widely discussed the relationship between nutrition and diet for low-income groups. In relation to empirical studies, the relationship between nutrition and diet for low-income groups extensively been researched $(1-3)$. Studies have consistently shown that individuals from lower socioeconomic (SES) group were more likely to consume a diet high in fat, low in micronutrient density, and a low intake of fruit and vegetables compared to those from higher socioeconomic status (4-7). The high refined grain added sugar, and added fats' diet generally, cost lesser than a healthy diet composed of lean meat, fresh fruits, and vegetables. Such a diet had led a segment of the population to an expansive exposure to an unhealthy diet (8). Thus, obesity is one of the most common problems related to an individual's dietary pattern. Studies have shown a significant relationship between obesity and low-income communities $(3,9)$.

Unfortunately, single-parent women who are from the category of low-income groups are among the most vulnerable group (10-13) yet remains understudied. Traditionally, single mothers refer to those who have been widowed, divorced, or unmarried and have a dependent child or children. Since women are usually more involved with food purchase and preparation, their choices and selection of food would affect the 
whole family. The situation for a broken family, particularly those with lower SES, differs from a typical family. Their spouseless condition eventually affects their financial condition. Limited studies have been conducted regarding nutrition and dietary patterns among single mothers. A few studies have attempted to explore the issue. A study by Jovanovski and Cook (14) explores the food provisioning practices of low-income single mothers affected by market-driven welfare reforms in Australia and the effects on the nutritional health and wellbeing of women and their children. Another study by McKenzie and McKay (15) investigate the impact of welfare payment changes on low-income single mother's food choices and strategies. This study suggests that food had become an expense that could be tightly managed, limited, or foregone for these families. Though, there are scanty studies concern on the dietary aspect of lowincome single mothers, in particular concerning the dietary intake recommendation of the food guide.

Generally, it is difficult for people to decide what proportion of their overall diet comprises each of the macronutrients. Hence, to improve dietary guidelines as a useful instrument for use among the population, most countries, through related agency or ministry has emphasised intake from major food groups through the Food Guide Pyramid. The Food Guide Pyramid is a generally recognised nutrition education tool which the public can use to track their dietary intake. It is on food packaging and is educated through nutrition-based education programs such as in schools and the community. The Pyramid promotes a daily diet based on the consumption of a recommended number of servings from each of the five major food groups. It also suggests healthy food choices within each food group.

Even though the benefit to follow the Food Guide Pyramid is emphasised, to our knowledge, there are a small number of studies specifically on the nutrition issue concerning dietary guidelines or the Food Guide Pyramid among low-income single mothers. A study by Glanville and Mcintyre (16) investigate dietary adequacy of low-income lone mothers and their children in Atlantic Canada using Canada's Food Guide to Healthy Eating and the Nutrition Recommendations for Canadians. The results indicated that the diet quality of low-income lone mothers was poor or in need of improvement, with no mother having a proper diet. Moreover, the diet quality of children varied by age.

Another study that concern on the diet quality and nutritional information was by Machín, Giménez (17). Though, the study on low-income mothers; and not focuses on single mothers. He investigates the influence of nutritional information on how low-income mothers select food for their children. Results showed that low-income mothers do not deliberate nutritional information when selecting food for their children. Traditional nutritional labelling perceived as complex, difficult to find and to understand. The results suggest the need to implement simplified nutritional labelling and to regulate the use of nutrition claims on products targeted at children.

Generally, there are still lacking research on dietary related issues among low-income single mothers. Therefore, this present study aims to examine food-based dietary patterns among low-income single mothers. Specifically, this study investigates and describe food consumption and the dietary related issue of lean/normal and overweight/obese low-income, single mothers in one of the states in Malaysia; Terengganu. There are at least three contributions to this study. Firstly, the study to highlight awareness 
among low-income single mothers on the dietary recommended intake based on Malaysian food. Secondly, the study is to fill the gap on dietary habit related research among low-income single mothers. Lastly, this study provides insight knowledge by employing an Eastern perspective of dietary and nutrition issues among low-income women which predominantly dominated by the Western counterpart.

\section{Methods}

This study employed a purposive sampling method, which involved single mothers from Kuala Nerus District, Terengganu. After obtaining permission from the State and District Department of Kuala Nerus, Terengganu, data were collected between July 2018 and November 2018. In total, 519 single mothers participated voluntarily in the study (response rate $=91.5 \%$ ). The inclusion criteria of subjects are single mothers with a household income of RM3000 or less, based on the categorisation of low-income groups in Malaysia (18).

A self-administered questionnaire developed for this study. The questionnaire was divided into three sections; section A to obtain demographic information of respondents; section B is to identify food intake with referring to the Malaysian Food Pyramid guideline and section $C$ on the dietary-related questions. In section $B$, the subjects were given information on the Malaysian Food Pyramid Guideline (Figure 1). The questionnaire was piloted for its validity and reliability.

The categorisation of food was based on the Malaysian Food Pyramid, which divided into four levels of food groups. The guideline is for getting the right balance of nutritious foods within the calorie range. The Malaysian Food Pyramid defines healthy eating as high consumption of vegetables and fruits (eat plenty), an adequate amount of carbohydrates (eat adequately), a moderate number of dairy products, protein and legumes (eat in moderation) and a small amount of fat, oil, sugar and salt (eat less). The subjects were required to rank their daily food intake based on the Malaysian Food Pyramid categories. They were asked to rank between 1 and 4, where 1 =plenty, $2=$ adequately, $3=$ moderation and $4=$ less of food consumption. Data obtained were analysed using tables and percentages. The ranking to identify the choice or preferences of respondents towards food consumption. Even though the approach is merely to rank their food preferences based on the Malaysian Food Pyramid, the method is justified as a first step in identifying the food consumption and the dietary habits among low-income single mothers, in particular to getting responses on their understanding of the food pyramid. By taking the consideration of their educational background, with secondary schools qualification dominated the educational background of the respondents, the ranking approach is understandable by them. It is has been tested and validated during the pilot study.

The Chi-square test was used to explore the differences in the measured parameters between the lean/normal and overweight/obese subjects. The p-values of $0.01,0.05$ and 0.10 and less were considered to be statistically significant. All statistical analyses were carried out using IBM SPSS (version 22.0) 


\section{Results}

Table 1 shows the demographics of subjects by age, household income and education level. Subjects were aged between 21 and 60 , and more than 61 . Overall, $59 \%$ of the subjects were overweight/obese $(\mathrm{BMI}>25)$ and $41 \%$ of them were lean/normal $(\mathrm{BMI}<25)$. Next, the results showed that 67 of the subjects above 61 years of age were lean/normal (BMI < 25), whereas 97 of them were overweight/obese $(\mathrm{BMI}>25)$. Based on household income, all of the subjects earned less than RM3000. Besides that, the majority of the subjects completed the Malaysian certificate of education; 86 respondents of lean/normal $(\mathrm{BMI}<25)$ and 119 of them were overweight/obese $(\mathrm{BMI}>25)$.

Table 2 shows the food intake between lean/normal and overweight/obese participants. The subjects were required to rank their daily food intake based on the Malaysian Food Pyramid categories. They were asked to rank between 1 and 4, where $1=$ plenty, 2=adequately, 3=moderation and 4=less of food consumption. Both of BMI groups rank the carbohydrates food categories as plenty consumption with $59.8 \%$ of the subjects $(\mathrm{BMI}<25)$ and $73.4 \%$ of the subjects $(\mathrm{BMI}>25)$ consumed carbohydrates daily. Secondly, $37.4 \%$ of the subjects (BMI $<25)$ preferred fruits and vegetables adequately, as part of their second dietary options. Additionally, $39.7 \%$ of them (BMI > 25) chose fruits and vegetables in moderation as their third choice. The results proved significant differences between subjects' carbohydrate intake ( $\mathrm{p}$ value 0.006 ) and fruits and vegetables ( $p$-value 0.010 ). Both groups of subjects had chosen dairy, protein and legumes as adequately. Next, subjects ranked fats, oil, sugar and salt as their least consumption. Results proved that fats, oil, sugar and salt were consumed minimally daily. There was no significant difference in food intake for the above-mentioned food categories $(p>0.05)$ between the lean/normal and overweight/obese groups. 
Table 1

Demographics of lean/normal and overweight/obese of low-income single mothers

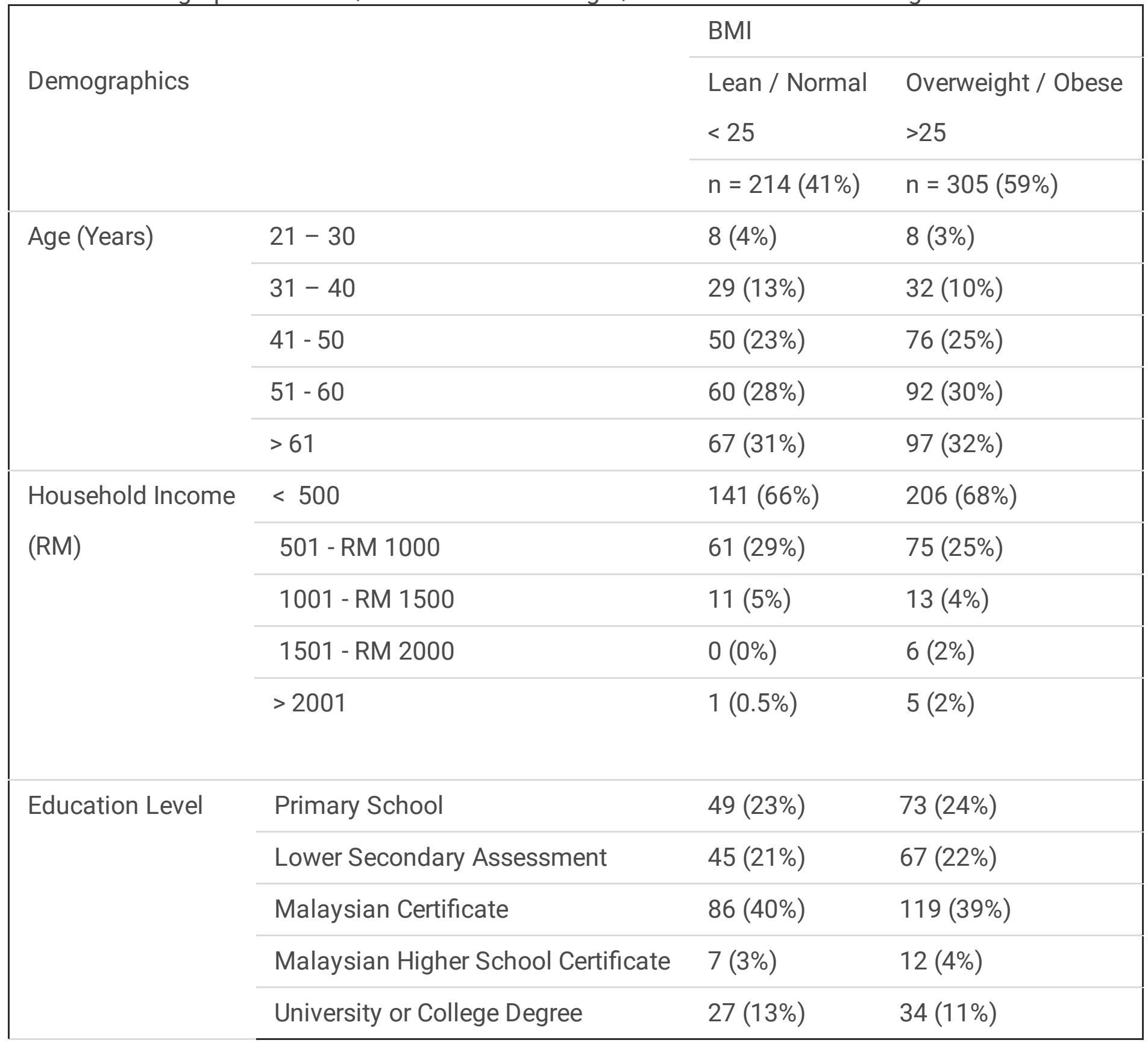


Table 2

Differences in food consumption between lean/normal and overweight/obese of low - income single mothers

\begin{tabular}{|c|c|c|c|c|}
\hline \multirow[t]{4}{*}{ Food Categories } & & \multicolumn{2}{|l|}{ BMI } & \multirow[t]{4}{*}{ p-value* } \\
\hline & & Lean / Normal & Overweight / Obese $>25$ & \\
\hline & & \multicolumn{2}{|l|}{$<25$} & \\
\hline & & $n=214$ & $n=305$ & \\
\hline Fat, Oil, & 1 & $14(6.5 \%)$ & $14(4.6 \%)$ & 0.553 \\
\hline Sugar and & 2 & $14(6.5 \%)$ & $14(4.6 \%)$ & \\
\hline \multirow[t]{2}{*}{ Salt } & 3 & $21(9.8 \%)$ & $34(11.1 \%)$ & \\
\hline & 4 & $165(77.1 \%)$ & $243(79.7 \%)$ & \\
\hline Milky, Dairy & 1 & $32(15.0 \%)$ & $38(12.5 \%)$ & 0.767 \\
\hline Products, Fish, & 2 & $88(41.1 \%)$ & $136(44.6 \%)$ & \\
\hline Chicken, Meat & 3 & $83(38.8 \%)$ & $118(38.7 \%)$ & \\
\hline and Legumes & 4 & $11(5.1 \%)$ & $13(4.3 \%)$ & \\
\hline Vegetables, & 1 & 40 (18.7\%) & $29(9.5 \%)$ & $0.010^{\mathrm{a}}$ \\
\hline \multirow[t]{3}{*}{ Fruits } & 2 & $80(37.4 \%)$ & $119(39.0 \%)$ & \\
\hline & 3 & $79(36.9 \%)$ & $121(39.7 \%)$ & \\
\hline & 4 & $15(7.0 \%)$ & $36(11.8 \%)$ & \\
\hline Rice, & 1 & $128(59.8 \%)$ & $224(73.4 \%)$ & $0.006^{b}$ \\
\hline Noodles, Bread & 2 & $33(15.4 \%)$ & $35(11.5 \%)$ & \\
\hline and Cereals & 3 & $30(14.0 \%)$ & $31(10.2 \%)$ & \\
\hline
\end{tabular}




$423(10.7 \%) \quad 15(4.9 \%)$

Note: * Categorical variables presented as $\mathrm{n}(\%)$ and the differences in food consumption tested using Chi-square test.

$a, b$ indicates significant at the level of 0.05 
Table 3

Dietary related questions between lean/normal and overweight/obese low-income single mothers

\begin{tabular}{|c|c|c|c|c|}
\hline & & BMI & & $\mathrm{p}-$ \\
\hline & & $\begin{array}{l}\text { Lean / } \\
\text { Normal }\end{array}$ & Overweight/Obese $>25.0$ & \\
\hline & & $<25.0$ & & \\
\hline & & $\mathrm{n}=214$ & $\mathrm{n}=305$ & \\
\hline In general, you would say & Poor & $2(0.9 \%)$ & $6(2.0 \%)$ & \\
\hline your diet is: & Fair & $11(5.1 \%)$ & $26(8.5 \%)$ & $0.055^{a}$ \\
\hline & Good & $69(32.2 \%)$ & $124(40.7 \%)$ & \\
\hline & $\begin{array}{l}\text { Very } \\
\text { Good }\end{array}$ & $104(48.6 \%)$ & $119(39.0 \%)$ & \\
\hline & Excellent & $28(13.1 \%)$ & $30(9.8 \%)$ & \\
\hline In general, you would say & Poor & $1(0.5 \%)$ & $5(1.6 \%)$ & \\
\hline your health is: & Fair & $12(5.6 \%)$ & $32(10.5 \%)$ & $0.000^{\mathrm{b}}$ \\
\hline & Good & $49(22.9 \%)$ & $101(33.1 \%)$ & \\
\hline & $\begin{array}{l}\text { Very } \\
\text { Good }\end{array}$ & $95(44.4 \%)$ & $130(42.6 \%)$ & \\
\hline & Excellent & $57(26.6 \%)$ & $37(12.1 \%)$ & \\
\hline & Yes & $178(83.2 \%)$ & $258(84.6 \%)$ & 0.666 \\
\hline & No & $36(16.8 \%)$ & $47(15.4 \%)$ & \\
\hline & Yes & $132(61.7 \%)$ & $179(58.7 \%)$ & 0.493 \\
\hline $\begin{array}{l}\text { Is the food selection } \\
\text { based on the same level } \\
\text { of the food pyramid in a } \\
\text { week? }\end{array}$ & & & & \\
\hline
\end{tabular}


How do you prepare your food daily?
Cook by $\quad 201(93.9 \%) \quad 288(94.4 \%)$

$$
13(6.1 \%) \quad 17(5.6 \%)
$$

Purchase

ready

food

Do you buy food supplies at the grocery store?

No $\quad 96(44.9 \%) \quad 148(48.5 \%)$

$\begin{array}{llll}\text { Yes } & 91(42.5 \%) & 133(43.6 \%) & 0.806\end{array}$

Do you buy food supplies at the wet market?

No

Yes
$123(57.5 \%) \quad 172(56.4 \%)$

$111(51.9 \%) \quad 174(57.0 \%)$

0.243

Do you buy food supplies at the supermarket?

\begin{tabular}{lcccc} 
& No & 103(48.1\%) & $131(43.0 \%)$ \\
\hline $\begin{array}{l}\text { Are you satisfied with } \\
\text { your }\end{array}$ & Yes & $178(83.2 \%)$ & $245(80.3 \%)$ & 0.410 \\
$\begin{array}{l}\text { food consumption } \\
\text { patterns compared to the } \\
\text { food pyramid? }\end{array}$ & No & $36(16.8 \%)$ & $60(19.7 \%)$ & \\
\hline
\end{tabular}

Additionally, subjects stated their opinions on dietary related issues (Table 3). They were asked to rate their diet based on five different scales from poor to excellent. About $48.6 \%$ of the lean/normal group $(\mathrm{BMI}<25)$ indicated that their overall diet was very good. Next, $32.2 \%$ of them stated that their diet was generally good, and only $0.9 \%$ of them labelled their diet as poor. Nonetheless, $40.7 \%$ of the subjects from 
the overweight/obese group (BMI > 25) mentioned that they have a good diet. About $39 \%$ of them indicated a very good diet and only $2 \%$ of them pointed out that they have a poor diet. As a result, there was a significant difference between both groups' diet status $(p=0.055)$.

Next, the subjects rated poor, fair, good, very good and excellent on the five scales to examine their health status. About $44.44 \%(\mathrm{BMI}<25)$ and $42.6 \%(\mathrm{BMI}>25)$ stated that health was in a good status. Therefore, more than $50 \%$ of them indicated that their health status was good and beyond. Nevertheless, only $1.6 \%$ of those with a $\mathrm{BMI}>25$ and $0.5 \%$ with a $\mathrm{BMI}<25$ mentioned that their health was in poor condition. Hence, there was a significant difference between the subjects and their health status $(p=0.000)$.

It was also crucial for the present study to know if the subjects were able to comprehend the Malaysia Food Pyramid. A total of $83.2 \%(\mathrm{BMI}<25)$ and $84.6 \%(\mathrm{BMI}>25)$ of the subjects agreed that they understood the guidelines. Additionally, $61.7 \%$ of the subjects $(\mathrm{BMI}<25)$ and $58.7 \%(\mathrm{BMI}>25)$ indicated that their weekly food consumption was based on the quantity of food determined by the Malaysia Food Pyramid. Besides that, $93.9 \%(\mathrm{BMI}<25)$ and $94.4 \%(\mathrm{BMI}>25)$ of the subjects prepared the food themselves daily. Only a small number of subjects from both groups purchased ready-made food for their daily meals. About $51.9 \%(\mathrm{BMI}<25)$ and $57 \%(\mathrm{BMI}>25)$ of the subjects preferred to get their food supplies from the supermarket. On the other hand, 55.1\% $(\mathrm{BMI}<25)$ and $51.5 \%(\mathrm{BMI}>25)$ preferred the grocery store. Finally, 42.5\% (BMI < 25) and 43.6\% (BMI > 25) of the subjects chose wet markets to shop for their food supplies. Overall, 83.2\% $(\mathrm{BMI}<25)$ and $80.3 \%(\mathrm{BMI}>25)$ of the subjects were satisfied with the food consumption pattern based on the Malaysia Food Pyramid. Both groups did not exhibit significant differences in terms of understanding the Malaysia Food Pyramid. Additionally, there were no differences in their daily food preparation, food purchasing, and food-intake satisfaction $(p>0.05)$.

\section{Discussion}

Most of the present literature stated that the lower SES group chose foods that were cheap and less healthy as a result of their financial constraints. Research findings showed that those from lower SES group were much affected by the increasing food price, which might have adverse effects on nutritional and health status (19). However, our study had outlined several factors, which will be thoroughly discussed. This study examined the food consumption of low-income, single mothers. They were categorised based on their respective groups; lean/normal $(\mathrm{BMI}<25)$ and overweight/obese $(\mathrm{BMI}>25)$. Next, they had been asked to rank their food consumption preferences based on the Malaysia Food Pyramid. The findings showed a difference between lean/normal and overweight/obese subjects food consumption pattern for the vegetables and fruits category. Those who had lean/normal body weight consumed fruits and vegetables adequately. On the other hand, subjects who were overweight/obese consumed fruits and vegetables in moderation based on the Malaysia Food Pyramid. Several research findings had supported the relationship between a low BMI and the intake of fruit and vegetables $(20,21)$. Although there were findings highlighted that lower SES groups consume fewer fruits and vegetables daily $(22,23)$, this study proved otherwise. The study, therefore, showed that the subjects still consumed and prioritise to add vegetables and fruits categories in their food intakes. 
On the other hand, both groups consumed a high amount of carbohydrates. Nevertheless, those who were overweight/obese still did indulge more. This was a predictable result as rice is Malaysia's staple food. These choices were typical because of Malaysian culture. Malaysia is part of the Southeast Asian region of countries and is known as the rice bowl of Asia. Therefore, Malaysians consume a lot of carbohydrate type of foods (24). However, excess intake of carbohydrates could lead to health problems such as obesity (25). Overall, the findings indicated that the majority of the subjects were obese (BMI > 25). Meanwhile, foods such as dairy, protein and legumes were taking in adequate and least consumption of fat, oil, sugar and salt food category. Based on the Malaysia Food Pyramid, people should consume fats, oil, sugar and salt in a little amount. As such, subjects from both groups were aware, and the majority of them consumed less fat, oil, sugar, and salt.

Generally, the results showed that the food consumption for both groups was inconsistent for one food category; vegetables and fruits, despite the recommendations outlined by the Malaysia Food Pyramid. Subjects who were overweight/obese $(\mathrm{BMI}>25)$ consumed plenty of carbohydrates and consumed vegetables and fruits in moderation. Meanwhile, subjects who were lean/normal $(\mathrm{BMI}<25)$, consumed plenty of carbohydrates and consume vegetables and fruits in adequate Nonetheless, there were only minor discrepancies because of Malaysia's staple food. Foods such as dairy, protein, legumes, oil, sugar and salt were equivalent to the guidelines. In general, subjects with low SES had dietary intake recommendations that were closely linked to the Malaysia Food Pyramid. The findings obtained from this study did not coincide with the hypothesis of the research by (4-7), which stated that subjects from a low socioeconomic status chose to consume unhealthy food. It was probably due to the gender of the subjects in the research; women. The women's diet was qualitatively and quantitatively different from men (26). Women were in charge of purchasing, preparing, cooking, and consuming food that is considered healthy, besides that their diet complemented the dietary guidelines. Hence, the results of the present study were consistent with the findings by Inglis et.al (26). The subjects were aware of the need to adhere to the food pyramid recommendations. It was concluded based on the significant number of subjects who were satisfied with their food consumption based on the Malaysian Food Pyramid. Besides that, the food preparation also played a vital role in the study too. The findings showed that the majority of the subjects from both groups cooked food themselves. Therefore, they were aware of their choices of ingredients and food preparations. Besides, more than $50 \%$ of the subjects perceived their health and diet to be in good condition.

Several limitations to the present study should be highlighted. First, the study used the Malaysian Food Pyramid as a tool for getting information on nutrition and dietary patterns among respondents. Ideally, the information asked based on the specific amount of food intake on five food groups. For example, how many servings of food consumption from each level; Level 1 (rice, noodles, bread and cereals), Level 2 (vegetables and fruits), Level 3 (milky, dairy products, fish, chicken, meat and legumes) and Level 4 (fat, oil, sugar and salt). However, based on the pilot study, we found the respondents difficult to state and interpreted the specific amount of food servings. Alternatively, we adopt the terms; eat plenty (vegetables and fruit), eat adequately (carbohydrates), eat-in moderation (dairy products, protein and legumes) and eat less (fat, oil, sugar and salt). We have tested a few ways and decided to use the ranking approach in 
elucidating the dietary information based on the food pyramid. Second, most of the respondents are selfemployed, and it is a challenge to gather them within the specified time and date. It takes a toll in terms of duration, though, we managed to get a good number of respondents voluntarily through the Kuala Nerus District Single Mothers Association, with the assistance of the State government.

\section{Conclusion}

This study aimed at investigating and describe food consumption and the dietary related issue of lean/normal and overweight/obese low-income, single mothers in one of the states in Malaysia; Terengganu. Our study is one of the pioneering studies to shed light on this important; however, underresearched topic in Malaysia's context. It provided evidence that there are awareness and close consistent of the dietary recommended intake to Malaysian Food Pyramid among low-income single mothers. Besides, the results also indicated the positive dietary behaviour in food consumption among most of the low-income single mothers in Terengganu, Malaysia. The findings have rebutted the previous related studies that stated the poor diet quality among low-income lone mothers. These results highlight the increasing concern of the dietary intake and health-conscious of single mothers, despite their lower SES status. Therefore, the present study provides essential findings to promote healthy eating based on the Malaysian Food Pyramid, in particular, to lower-income groups. The present study was, therefore, a groundbreaking attempt at examining the dietary intake of low-income single mothers in Malaysia. This study had provided relevant information and also call for a necessary action from stakeholders to support a healthy diet and nutrition, not limited to low-income single mothers', but also other lower SES groups.

\section{Abbreviations}

BMI: Body mass index; SES: Socioeconomic status

\section{Declarations}

\section{Acknowledgements}

The authors thank the data collection team members and all the representatives of the Single Mothers' Association of Kuala Nerus District, Terengganu, who assisted us during the data collection process.

\section{Funding}

This study was funded by the Universiti Malaysia Terengganu Research Grant (Grant number: 53259).

\section{Authors' contributions}


$\mathrm{NHK}$ and NHA performed the data analysis and interpreted the results. SM and YU participated in the study conceptualisation, study design, data interpretation, manuscript preparation, and finalisation. NA conceived the study and collected the data. SM and NEH contributed to the critical revision of the manuscript. All authors read and approved the final version of the manuscript.

Suriyani Muhamad (SM), Yulita (YU), Nor Ermawati Hussain (NEH), Noorhaslinda Kulub Abdul Rashid (NHK), Noor Haslina Mohamad Akhir (NHA) and Nizam Ahmat (NA).

\section{Availability of data and materials}

The datasets during and/or analysed during the current study are available from the corresponding author on reasonable request.

\section{Competing interests}

The authors declare that they have no competing interests.

\section{Consent for publication}

Not applicable

\section{Ethics approval and consent to participate}

The study protocol and permission to conduct this study were approved by the Research Management Centre, Universiti Malaysia Terengganu.

\section{References}

1. Attree P. Low-income mothers, nutrition and health: a systematic review of qualitative evidence. Maternal Child Nutrition. 2005;1(4):227-40.

2. Bove CF, Olson CM. Obesity in Low-Income Rural Women: Qualitative Insights About Physical Activity and Eating Patterns. Women Health. 2006;44(1):57-78.

3. McLaren L. Socioeconomic status and obesity. 2007. p. 29-48.

4. Smith GD, Brunner E. Socio-economic differentials in health: The role of nutrition. Proceedings of the Nutrition Society. 1997;56(1A):75-90.

5. Giskes K, Turrell G, Patterson C, Newman B. Socio-economic differences in fruit and vegetable consumption among Australian adolescents and adults. Public Health Nutrition. 2002;5(5):663-9. 
6. Mishra G, Ball K, Arbuckle J, Crawford D. Dietary patterns of Australian adults and their association with socioeconomic status: results from the 1995 National Nutrition Survey. Eur J Clin Nutr. 2002;56(7):687-93.

7. Cheon BK, Hong Y-Y. Mere experience of low subjective socioeconomic status stimulates appetite and food intake. Proceedings of the National Academy of Sciences. 2017;114(1):72 - 7.

8. Dammann KW, Smith C. Factors affecting low-income women's food choices and the perceived impact of dietary intake and socioeconomic status on their health and weight. J Nutr Educ Behav. 2009;41(4):242-53.

9. Townsend MS. Obesity in Low-Income Communities: Prevalence, Effects, a Place to Begin. J Am Diet Assoc. 2006;106(1):34-7.

10. Lu Y-C, Walker R, Richard P, Younis M. Inequalities in poverty and income between single mothers and fathers. International Journal of Environmental Research Public Health. 2020;17(1):135.

11. Hübgen MS. Understanding lone mothers' high poverty in Germany: Disentangling composition effects and effects of lone motherhood. Advances in Life Course Research. 2020:100327.

12. Kramer KZ, Myhra LL, Zuiker VS, Bauer JW. Comparison of poverty and income disparity of single mothers and fathers across three decades: 1990-2010. Gender Issues. 2016;33(1):22-41.

13. Loibl C. 26 Living in Poverty: Understanding the Financial Behaviour of Vulnerable Groups. UK: CENTRE FOR DECISION RESEARCH, UNIVERSITY OF LEEDS; 2018. p. 421.

14. Jovanovski N, Cook K. How Australian welfare reforms shape low-income single mothers' food provisioning practices and their children's nutritional health. Critical Public Health. 2020;30(3):34051.

15. McKenzie HJ, McKay FH. Food as a discretionary item: The impact of welfare payment changes on low-income single mother's food choices and strategies. Journal of Poverty Social Justice. 2017;25(1):35-48.

16. Glanville NT, Mcintyre L. Diet quality of Atlantic families headed by single mothers. Canadian Journal of Dietetic Practice Research. 2006;67(1):28-35.

17. Machín L, Giménez A, Curutchet MR, Martínez J, Ares G. Motives underlying food choice for children and perception of nutritional information among low-income mothers in a Latin American country. Journal of Nutrition Education Behavior. 2016;48(7):478-85. e1.

18. Malaysia DoS. Report of household income and basic amenities survey 2014. Department of Statistics Malaysia Putrajaya; 2015.

19. Green R, Cornelsen L, Dangour AD, Turner R, Shankar B, Mazzocchi M, et al. The effect of rising food prices on food consumption: systematic review with meta-regression. BMJ. 2013;346(jun17 1):f3703-f.

20. He K, Hu FB, Colditz GA, Manson JE, Willett WC, Liu S. Changes in intake of fruits and vegetables in relation to risk of obesity and weight gain among middle-aged women. International Journal of Obesity. 2004;28(12):1569-74. 
21. Lin B-H, Morrison RM. Higher Fruit Consumption Linked With Lower Body Mass Index. Food Review/ National Food Review. 2002;25(3):1-5.

22. Mackenbach JD, Brage S, Forouhi NG, Griffin SJ, Wareham NJ, Monsivais P. Does the importance of dietary costs for fruit and vegetable intake vary by socioeconomic position? Br J Nutr. 2015;114(9):1464-70.

23. Dijkstra SC, Neter JE, Brouwer IA, Huisman M, Visser M, Van Lenthe FJ, et al. Socioeconomic differences in the change of fruit and vegetable intakes among Dutch adults between 2004 and 2011: the GLOBE study. Public Health Nutrition. 2018;21(9):1704-16.

24. Ooraikul B, Sirichote A, Siripongvutikorn S. Southeast Asian Diets and Health Promotion. Totowa: Humana Press; 2008. pp. 515-33.

25. van Dam RM, Seidell JC. Carbohydrate intake and obesity. Eur J Clin Nutr. 2007;61(S1):75-99.

26. Inglis V, Ball K, Crawford D. Why do women of low socioeconomic status have poorer dietary behaviours than women of higher socioeconomic status? A qualitative exploration. Appetite. 2005.

\section{Figures}

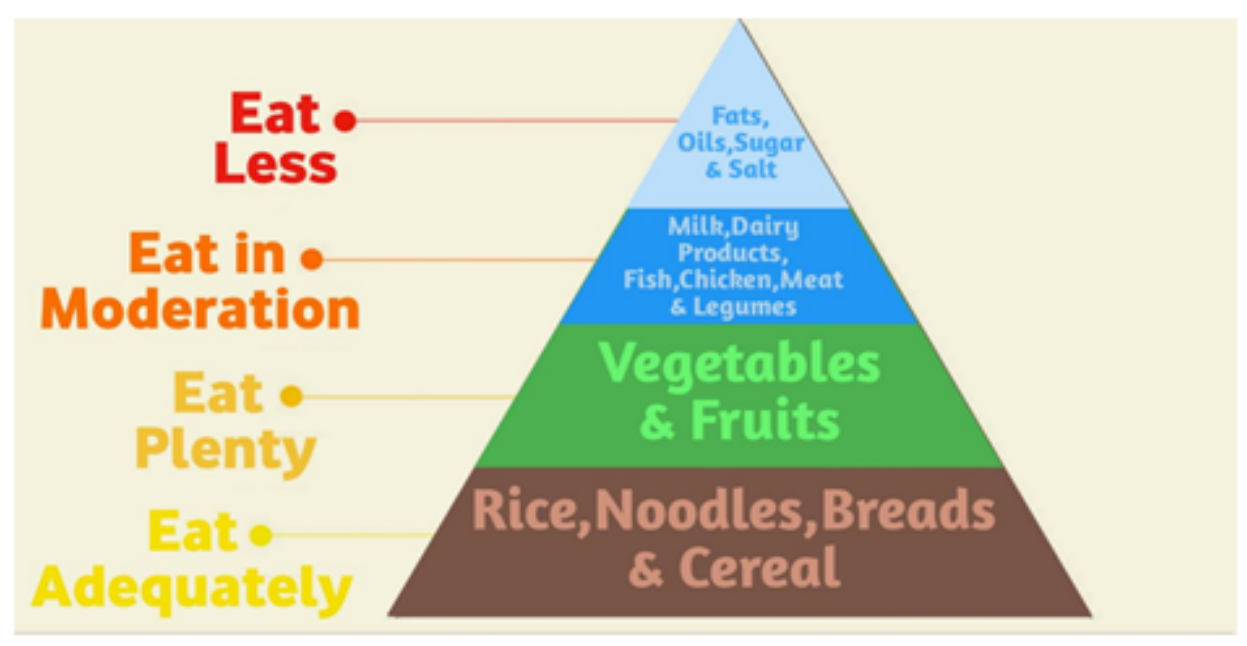

\section{Figure 1}

Malaysian Food Pyramid 